\title{
Periodística como disciplina universitaria en España: una propuesta
}

Recibido: 05/09/2018

Aprobado por pares: 03/12/2019

\author{
Fernando López-Pan ${ }^{1}$ \\ Jorge Rodríguez-Rodríguez ${ }^{2}$ \\ Ignacio de Lorenzo-Rodríguez $z^{3}$
}

Enviado a pares: $21 / 09 / 2018$

Aceptado: 10/02/2019

DOI: $10.5294 /$ pacla.2020.23.3.6

Para citar este artículo / to reference this article / para citar este artigo López-Pan, F., Rodríguez-Rodríguez, J. y de Lorenzo-Rodríguez, I. (2020). Periodística como disciplina universitaria en España: una propuesta. Palabra Clave, 23(3), e2336. https://doi.org/10.5294/pacla.2020.23.3.6

\section{Resumen}

Las disciplinas dentro de las áreas de conocimiento son transversales y se configuran con las aportaciones de diferentes culturas y países. En el campo de los estudios sobre el periodismo (como en muchos otros), el ímpetu de las perspectivas de raíz anglosajona ha dejado en la penumbra otras aproximaciones e intentos. Aunque toda tradición, al menos en la cultura occidental, aparece entreverada con las demás, también presenta unas peculiaridades que enriquecen el debate. Este artículo se marca como objetivo dar a conocer la tradición hispanoamericana y, especialmente, la española en lo que se refiere a las reflexiones acerca de los estudios sobre el periodismo como disciplina universitaria. La preocupación por dotar al periodismo de un estatuto disciplinar ha estado siempre presente, pero, sobre todo, con el paso de las escuelas a las universidades. En ese paso, en ese gozne, España se caracteriza por haber generado una intensa y prolongada discusión acerca de los elementos que definen el periodismo como una disciplina de rango universitario. Ese debate apenas ha tenido lugar en Hispanoamérica.

\footnotetext{
$\triangle$ https://orcid.org/0000-0002-2035-3431. Universidad de Navarra, España. lopezpan@unav.es

https://orcid.org/0000-0001-9077-6416. Universidad San Jorge, España. jmrodriguez@usj.es

https://orcid.org/0000-0001-6891-5440. Universidad de Navarra, España. idelore@unav.es
} 
La metodología se basa en la revisión de la bibliografía publicada al respecto, con especial atención a la de los autores pioneros: Martínez Albertos, Núñez-Ladèveze y Casasús. Dada la relevancia que esa reflexión ha tenido España, se desarrolla con más detalle ese debate y se formula como conclusión una propuesta renovada que define la periodística y describe su objeto de estudio, sus ámbitos, su naturaleza multidisciplinar y las metodologías de investigación de las que se auxilia.

\section{Palabras clave (Fuente: tesauro de la Unesco)}

Periodismo; redacción periodística; investigación; teoría; Hispanoamérica; España; periodística. 


\section{Journalism as an Academic Discipline in Spain: A Proposal}

\section{Abstract}

Disciplines within knowledge domains are cross-cutting and shaped by the contributions of cultures and countries. In the field of journalism studies (as in many others), the force of Anglo-Saxon perspectives has outshined other approaches and attempts. Although every tradition —at least in Western culture- intertwines with others, they also have peculiarities that enrich the debate. This article aims to introduce the Spanish-American tradition and, especially, the Spanish one regarding reflections on journalism studies as an academic discipline. The concern for endowing journalism with a disciplinary status has lingered on, particularly because of the passage from schools to universities. Here, in this transition, Spain is characterized by having sparked off a prolonged, intense debate about the elements that define journalism as an academic discipline. Such a discussion has hardly taken place in Latin America. The method is based on a literature review focused on pioneering authors such as Martínez Albertos, Núñez-Ladèveze, and Casasús. Given the relevance of this reflection in Spain, this article elaborates further on the debate and, as a conclusion, brings forward a renewed proposal for defining journalism and describing its subject matter, scope, multidisciplinary nature, and methods.

\section{Keywords (Source: Unesco Thesaurus)}

Journalism; journalistic writing; research; theory; Hispanic American; Spain; journalistic. 


\section{Jonalistica como disciplina universitária na Espanha: uma proposta}

\section{Resumo}

As disciplinas dentro das áreas de conhecimento são transversais e são configuradas como as contribuições de diferentes culturas e países. No campo dos estudos sobre o jornalismo (como em muitos outros), o ímpeto das perspectivas de origem anglo-saxã vem deixando na penumbra outras aproximações e propostas. Embora toda tradição, pelo menos na cultura ocidental, apareça permeada pelas demais, também apresenta peculiaridades que enriquecem o debate. Nesse sentido, este artigo tem o objetivo de demonstrar a tradição hispano-americana e, em especial, a espanhola no que se refere às reflexões sobre os estudos acerca do jornalismo como disciplina universitária. A preocupação por atribuir ao jornalismo um estatuto disciplinar sempre esteve presente, mas, principalmente, com o passar das escolas às universidades. No contexto de um jornalismo gonzo, a Espanha é caracterizada por ter gerado uma intensa e prolongada discussão sobre os elementos que definem o jornalismo como uma disciplina de caráter universitário. Esse debate é recente na América Hispânica. A metodologia está baseada na revisão da bibliografia publicada a respeito da temática, com ênfase na dos autores pioneiros: Martínez Albertos, Núñez-Ladèveze e Casasús. Tendo em vista a relevância que esta reflexão vem tendo na Espanha, é desenvolvido, com mais detalhes, o debate e é formulada, como conclusão, uma proposta renovada que define o jornalística como disciplina e descreve seu objetivo de estudo, seus âmbitos, sua natureza multidisciplinar e as metodologias de pesquisa nas quais está apoiado.

\section{Palavras-chave (Fonte: tesauro da Unesco)}

Jornalismo; redação jornalística; pesquisa; teoria; hispanoamérica; Espanha; jornalístico. 


\section{Introducción}

La preocupación por dotar al periodismo de un estatuto disciplinar ha estado siempre presente, pero, sobre todo, con el paso de las escuelas a las universidades. En ese paso, en ese gozne, España se caracteriza por haber generado un debate y una discusión apenas existente en Hispanoamérica. Un buen reflejo es el número monográfico publicado por la revista Anàlisi: quaderns de comunicació $i$ cultura en 2002 de la que hablaremos más adelante.

En el ámbito hispanoamericano, apenas hay reflexiones sobre el periodismo como disciplina académica; sí, obviamente, sobre el periodismo como tal. No obstante, y aunque se precisa acometer una investigación diacrónica de mayor envergadura que establezca las fases, las influencias profesionales y teóricas por cada país, sí es posible perfilar un esbozo sobre la evolución de los estudios en torno al periodismo en Iberoamérica de acuerdo con nuestro interesado enfoque. Así, podemos diferenciar tres periodos:

1. Consolidación de un estatus profesional que obliga a una formación reglada y que desemboca en la fundación de escuelas profesionales, según el paradigma dominante: el de las escuelas de periodismo estadounidenses. Se evidencia una "preocupación temprana [... ] por la formación de los comunicadores, que hoy hace que se dispongan de experiencias de un periodo de tiempo que, en muchos países, data de cincuenta o más años y que ha obligado a constantes reflexiones para afrontar los nuevos desafíos" (López García, 2010, p. 233).

2. Construcción de un andamiaje curricular con planes de estudios y preceptivas para la enseñanza del oficio, y que, con los años, deriva en la elevación de esos estudios a un rango universitario. El conocimiento de las nociones básicas de la praxis por parte de los aprendices requería que esas escuelas contaran con un acervo bibliográfico y preceptivo que se obtuvo por dos vías confluyentes. Por un lado, la traducción, a partir de 1940 —en Argentina y en México — de obras canónicas de autores estadounidenses (Bond y Rivers, 1969; Charnley, 1971; Copple, 1968; Hohenberg, 1962; Johnson y Harris, 1970; Steinberg y Bluem, 1972; Weill, 1941). Por otro, la elaboración de (escasos y, al inicio, incipientes) manuales de redacción periodística 
en español de inspiración anglosajona, a partir de la década de 1960 (Aceves, 1963; Borrego, 1963; Cortez, 1961; Del Río, 1978; Hall y Merino, 1995; Rojas, 1976; Leñero y Marín, 1986; Romero, 1959; Santamarina, 1960; Santibáñez; 1974; Ulibarri, 1994, entre otros).

El influjo de la preceptiva periodística anglosajona se evidencia en las dos obras fundacionales de la manualística latinoamericana, editadas en Argentina (Santamarina, 1960; Romero 1959): ${ }^{4}$ además de asumir el canon de la retórica objetivista y de utilizar innumerables referencias de obras originales en inglés, ${ }^{5}$ los dos autores reclaman la incardinación de los estudios de periodismo a nivel universitario, tal como ocurría en los Estados Unidos. Ambos defienden el modelo de la Escuela de Periodismo de la Universidad de Columbia (1912). Ello les lleva a compilar para su imitación los planes de estudio de las escuelas de periodismo más influyentes de los Estados Unidos, América Latina y España de ese momento, así como una extensa "guía de publicaciones" de los diarios y revistas de referencia en esos tres ámbitos geográficos.

La reivindicación del patrón pedagógico norteamericano y la defensa del estatus universitario de los estudios de periodismo va a ser una constante en las preceptivas de las década de 1960 y 1970, hasta el punto de que Ávila, en su obra El periodismo y su filosofía (1963), llega a proponer al Gobierno venezolano que envíe a reporteros de la Asociación Venezolana de Periodistas para formarse y replicar en su país los modelos docentes de las escuelas de periodismo de la Universidad de Nueva York, la Universidad de Columbia y la Northwestern University, centros que él había visitado en la década de 1940, cuyas enseñanzas volcó en la asignatura Teoría y Práctica del Periodismo, en la Universidad Libre de Ciencias y Bellas Artes de Venezuela.

3. Un temprano y fugaz intento de teorización sobre una "ciencia del periodismo" bajo el amparo de teorías procedentes de la sociología, la psicología social, la filología y disciplinas afines de influencia alemana, francesa, norteamericana y, en menor medida, española. Aun-

4 Hay bibliografía sobre periodismo publicada en años anteriores, pero tiene un carácter más historiográfico que preceptivo. Por esa razón, no la hemos considerado en nuestro estudio.

5 Entre otras obras, citan las de Reschke (1951), Rae (1952), Westley (1953), Miller (1955) y Mott (1962). 
que los manualistas no desarrollan reflexiones académicas sobre el periodismo como disciplina (su cometido principal es el de dotar de herramientas redaccionales y reporteriles a los alumnos), muy pronto se subraya la necesidad de que los estudios de la profesión tengan una sólida base científica, tarea en la que, según Aceves (1963), catedrático de la Universidad Nacional Autónoma de México (UNAM), la Organización de las Naciones Unidas para la Educación, la Ciencia y la Cultura (Unesco) se había consagrado, como lo demostraba el establecimiento del primer Instituto de Estudios Superiores de Periodismo en Estrasburgo (Francia) y del Centro Latinoamericano de Estudios Superiores de periodismo (Ciespal) ${ }^{6}$ en Ecuador (Aceves, 1963, p. 24).

En ese sentido, más que una reflexión sobre el periodismo como disciplina científica, Ciespal promovió las investigaciones que abordan el periodismo como un gran campo de estudio (no obstante, dejamos para otra ocasión el análisis de la producción científica de Ciespal, porque este tema daría para unos o varios estudios que rebasan el objetivo de este trabajo), en tanto fenómeno social y cultural que puede $-\mathrm{y}$ debe - ser analizado por diversas disciplinas de las ciencias sociales. Así, se daba comienzo en Hispanoamérica al paradigma de investigación de corte sociológico-cualitativo sobre el fenómeno de la comunicación colectiva y sus relaciones con la economía, la política, la cultura y el desarrollo social. Esa integración de saberes centrada en la perspectiva científica social de los estudios de comunicación "delineó el futuro del área, donde periodismo y comunicación comenzaron a coexistir en medio de la falta de una clara definición" (Mellado, 2009, p. 195), lo que no ha favorecido una reflexión específica sobre el periodismo como disciplina científica de pleno derecho.

6 En efecto, durante la Conferencia General, décima reunión, París, 1958, se recomendó la creación del Centro Latinoamericano de Estudios Superiores de Periodismo (Ciespal), que fue promovido por ese organismo y por la Universidad Central del Ecuador, que, en 1959, le otorgó el rango de entidad universitaria autónoma. Entre sus objetivos, se encuentra promover la investigación y el conocimiento de los "diversos problemas que son objeto de estudio de la comunicología” (Ciespal, s. f.). Desde la década de 1960, Ciespal organizó seminarios y congresos para la formación de periodistas profesionales y profesores de periodismo, y dio prioridad a los estudios de carácter sociológico de escuelas de teóricas estadounidenses y europeas: Lerner, Schramm, Pye, Laswell, Lazarsfeld, Howland y Lewin (EE. UU.), al igual que Friedmany Terrou (Francia). 
Pero lo más relevante para este artículo son dos de los intentos metadisciplinares, dos propuestas para construir una "ciencia del periodismo".

1. En 1977, el abogado, escritor y periodista boliviano Raúl Rivadeneira Prada, formado en Alemania, Missouri y Harvard, publica en México Periodismo: la teoría general de los sistemas y la ciencia de la comunicación, obra que plantea de un modo más explícito la urgencia de unas "bases metodológicas de una futura ciencia del periodismo [las cursivas son nuestras]". No obstante, su aproximación es puramente formalista, pues somete a lo que denomina "señales impresas" de los diarios (los géneros periodísticos, los elementos gráficos y la organización de las secciones) a un análisis sistémico, bajo "el esquema tripartito de Pierce, Morris y Carnap: sintáctico, semántico y pragmático". Su objetivo es desentrañar "las complejas relaciones de los elementos que lo componen", así como los problemas del periodismo desde el ángulo de las modernas ciencias de la comunicación humana" (1977, p. 6). Lo interesante de su propuesta es que - al menos en la intencionalidad - marca una nueva etapa en los estudios de la profesión informativa, pues, según él mismo explica, ha llegado la hora de romper con "el manualismo que caracteriza a las innumerables obras que sobre periodismo se utilizan en escuelas y universidades para la formación práctica de futuros comunicadores" (p. 8). La interpretación del periodismo se debe auxiliar de disciplinas afines como las procedentes de la filología y la lingüística, y de otras de la esfera de las ciencias sociales, con el fin de construir una "ciencia periodística", en la que, a su parecer, han contribuido, desde distintas perspectivas, autores como Hagemann, Dovifat, Saussure, Chomsky, Paerce, Morris, Carnap, Lévy-Strauss, Schramm, Maletzke, Shanon y Wiewer, Lazarsfeld, Lewin, Lasswell, Hovland, entre otros (p. 25).

Para el teórico boliviano, tal "ciencia periodística" debe tener como objeto de estudio la cobertura, la elaboración, la recepción y distribución de las noticias, la opinión pública, los medios masivos, las fuentes de información (fuentes de acontecimiento, fuentes informantes y fuentes intencionales), la ética periodística, la objetividad y subjetividad en la elaboración de contenidos de los mensajes, los efectos de las informaciones sobre el receptor, la libertad de prensa, etc. Para él, los intereses científicos en es- 
tos y otros campos constituyen no leyes inmutables, sino acercamientos a los fenómenos a través de varias disciplinas. "La ciencia periodística es una ciencia multi- e interdisciplinaria. Sin contar con el auxilio de otras ciencias nada sabríamos acerca de la comunicación” (1977, p. 27). Estas ideas de Rivadeneira tendrán eco en la reflexión metadisciplinar española, como se verá más adelante.

2. Entrado el siglo XXI, ha sido la profesora mexicana Lourdes Romero, periodista y doctora en Filología por la Universidad Complutense, quien ha demandado la necesidad de "contar con una teoría del periodismo que explique de manera coherente el conjunto de saberes y prácticas que implican lo que llamamos periodismo" (2006b, p. 9). Romero (2006a) critica que, aun en 2006, algunos académicos defiendan que la profesión, al poseer una naturaleza práctica, solo precisa planes de estudio y preceptivas conducentes al aprendizaje de habilidades y competencias, y deje de lado contenidos teóricos que doten de capacidad reflexiva a los futuros informadores.

En lo especulativo, Romero es una de las herederas de las teorías disciplinares de los padres fundadores de la periodística en España, especialmente Martínez Albertos y Gomis. Nos encontramos ante una académica que se sirve de las aportaciones de ambos teóricos para sustentar sus propios postulados, continuadores de la tradición española. En concreto, la autora mexicana centra su interés en la objetividad periodística, la verdad de los hechos narrados y la manipulación del lenguaje como peaje ineludible en la escritura de los géneros periodísticos.

Así, sostiene, sirviéndose de Martínez Albertos (1978), que el periodista actúa como un "operador semántico" que manipula lingüísticamente una realidad bruta para elaborar un mensaje con una acertada codificación. Por otra parte, se basa en los postulados de Gomis (1991) para explicar que el periodista "organiza el relato" seleccionando los acontecimientos y decidiendo "qué contar y qué omitir", lo que demuestra "el grado de manipulación de quien organiza el material” (Romero, 2006b, p. 20). Subraya que la selección de los hechos no solo depende del grado de interés de las noticias, sino también de otros factores que van más allá de la supuesta trascen- 
dencia informativa y el interés del público, y que pasan (citando otra vez a Gomis) por las convenciones económicas y políticas (ideológicas) de los medios de comunicación, y que moldean la sociedad. El objetivo general de la autora es construir una teoría del periodismo orientada a un nuevo pacto/contrato (un nuevo periodismo heredero del nuevo periodismo) entre los periodistas y los lectores, en el que estos últimos sean perfectamente conscientes de la manipulación en las noticias, para que puedan juzgar sobre su veracidad con mayor criterio.

Las aportaciones metadisciplinares de Romero se nutren de la tradición española, que, como señalábamos, es la que más atención ha prestado a las reflexiones sobre el periodismo como disciplina académica. Y es precisamente esa tradición la que se aborda en las páginas siguientes, que estructuramos en tres epígrafes:

1. El paso de las escuelas de periodismo a la universidad: muy importante a nuestros efectos porque obliga a los candidatos de las asignaturas más prácticas a presentar proyectos docentes similares a los de sus colegas de otras disciplinas ya asentadas, es decir, se ven en la necesidad de reflexionar sobre la naturaleza, el objeto, la metodología y los ámbitos que abarcan sus materias.

2. Una breve revisión bibliográfica que mostrará el debate y la evolución desde la redacción periodística inicial a la propuesta de una periodística que aceptamos.

3. Una propuesta de objeto, ámbitos y naturaleza de la disciplina que denominamos, siguiendo a Casasús, periodística.

\section{El periodismo accede a la universidad en España: la redacción periodística}

El Decreto 2070/1971, de 13 de agosto, reguló, por primera vez en España, "los estudios de periodismo y demás medios de comunicación social en la Universidad”. Un mes después de la promulgación de la ley, las nuevas facultades arrancaron un proceso apresurado, con críticas por parte de al- 
gunos profesionales (Lazcano, 2013), que Martínez Albertos denominó un "bautismo por inmersión realmente salvaje" (1989a, p. 21). Y en el que asumieron un papel decisivo Gomis, ${ }^{7}$ Martínez Albertos, Núñez y Casasús, padres fundadores de la disciplina, según el monográfico de la revista Anàlisi: Quaderns de comunicació i cultura de 2002.

En sintonía con la formación que se impartía en las escuelas de periodismo existentes en España desde que se creara la primera del periódico El Debate en $1926,{ }^{8}$ el plan de estudios se articuló, como sintetiza Núñez (2002), en torno a unas enseñanzas complementarias (lengua, historia, etc.) y otras específicas, entre las que distingue la teoría de la información y de la comunicación, y la estructura de la información, a las que sitúa entre la psicología social y la sociología; el derecho de la información y la empresa informativa, que, desgajadas del derecho administrativo y de la organización de empresas, respectivamente, aportan conocimientos sobre el contexto de la actividad periodística; la redacción periodística, inicialmente concebida como un "híbrido de la lengua y la práctica periodística"; y el periodismo especializado, que abarcaba el "tratamiento de diversas materias difícilmente sistematizables” (Núñez, 2002, p. 86).

La asignaturas que pivotaban en torno al área de la redacción periodística, nacida en las primeras escuelas mencionadas, contaban con una tradición pedagógica, pero carecían de la dimensión investigadora, ineludible para legitimar su presencia de pleno derecho en las aulas universitarias, $y$ para que la tarea de los profesores no se limitara a enseñar habilidades profesionales y a publicar manuales para la docencia. Era evidente que la redacción periodística, si quería un reconocimiento universitario que no se redujera a un mero trámite legal, necesitaba definirse intelectualmente en los parámetros universitarios, con un tipo de investigación propio y una especialidad académica. Se comprende que, en ese entorno, los primeros

7 Sus aportaciones en el ámbito de la teoría del periodismo (Gomis, 1974, 1991) y de los géneros (Gomis, 1989) contribuyeron a la maduración de la redacción periodística; pero, a diferencia de los otros autores, no existe en su obra una reflexión sobre la disciplina como tal.

8 Tras la Guerra Civil (1936-1939), nacieron fuera de la universidad la Escuela Oficial de Periodismo (1942), la Escuela de Periodismo de la Iglesia (Madrid, 1960) y la Escuela de Periodismo de Barcelona (1968), adscrita a la de Madrid. Y, vinculado a los estudios universitarios, el Instituto de Periodismo, adscrito al Estudio General de Navarra (1958), más adelante, Universidad de Navarra. 
académicos se plantearan el estatuto de la redacción periodística como disciplina universitaria, ${ }^{9}$ con lo que ello implicaba: definir objeto de estudio, naturaleza, enfoque, metodología y principales ámbitos.

\section{Breve revisión histórico-bibliográfica: de la redacción periodística a la periodística}

Apenas transcurrido tres años de la llegada del periodismo a la universidad, el profesor de la Universidad Complutense, Martínez Albertos (1974), ya propone un primer horizonte disciplinar para la redacción periodística: una ciencia autónoma, del ámbito de las ciencias sociales, centrada en el mensaje informativo y, más específicamente, en el lenguaje periodístico y sus formas expresivas, sus géneros y sus estilos. Aunque, posteriormente, daría cabida al estudio de las fuentes, de los tipos de periodismo y de la organización profesional de los periodistas, mantuvo la centralidad de las formas expresivas, como se advierte en los distintos nombres que usa: redacción periodística, análisis del mensaje periodístico, lenguaje de los medios y escritura, y valoración de textos periodísticos. Desde el punto de vista metodológico, Martínez Albertos subrayaba la interdisciplinariedad que describía la redacción periodística como una ciencia puente entre disciplinas, pero con fronteras definidas que la separaban de otras cercanas, particularmente, la lengua.

Núñez, también iniciador del área, realiza ya en sus primeras obras sobre periodismo $(1977,1979)$ un esfuerzo explícito por definir la naturaleza de la disciplina en el nuevo entorno universitario. En trabajos posteriores (1991b, 1991c, 2002, 2004a, 2004b), mantendrá esa preocupación, pero partiendo de sus reflexiones sobre la formación universitaria de los periodistas y la tarea específica del profesor universitario de periodismo (no la del profesor de otras materias que enseña en una facultad de periodismo).

9 En el contexto de esta revista, merece la pena señalar que en sus comienzos el panorama de la literatura científica sobre periodismo en España era “desolador" (Casasús, 1987, p. 169), y, de hecho, los estudiosos españoles empleaban libros editados en Hispanoamérica para acceder a traducciones de autores estadounidenses o europeos (Dovifat, Hohenberg, Fraser Bond, Kayser, Morin o Copple), y también se nutrían del pensamiento de autores hispanoamericanos como Clemente Santamarina, Luis Alberto Romero, Mario Rojas Avendaño o Julio del Río Reynaga, entre otros. La mayor parte de las obras procedían de México y Argentina, y, en menor medida, de Ecuador y Venezuela. Posteriormente, han sido muy habituales las coautorías de profesores latinoamericanos en revistas académicas españolas. 
Al describir las dos actividades claves del mundo académico: docencia e investigación, trazaba el perfil de la disciplina y la dotaba de sentido. Como ese giro se inicia en 1991 y no cuaja del todo hasta 2002, dejamos para más adelante la síntesis de su planteamiento.

A finales de la década de 1980 e inicios de la década de 1990, Casasús, otro de los pioneros, aportó un interesante, útil y eficaz complemento a las reflexiones de los dos autores mencionados. En concreto:

1. Estudió la reflexión teórica que sobre el periodismo se había desarrollado desde los primeros tratados de periodismo hasta los trabajos más específicos de finales de la década de 1980 (Casasús, 1991b).

2. Propuso que la disciplina estudiara los procesos de producción, selección y valoración de hechos e ideas; los procesos de composición y comunicación social; las formas y modalidades de expresión; y los estilos y estructuras internas y externas que adoptan los mensajes de actualidad, y el resto de unidades redaccionales periodísticas (encuadradas en cualquiera de los géneros informativos, interpretativos, instrumentales y de opinión), cuando se canalizan a través de la prensa, la radio, la televisión u otros medios de comunicación de masas. (Casasús, 1989a, pp. 2 y 3 )

Un objeto de estudio así definido reclamaba una denominación en la que los aspectos expresivos no fueran dominantes, de ahí que ofreciera como alternativa el de periodística.

3. Esbozó una primera clasificación de ámbitos de la disciplina, que daba realce a otros aspectos además de las cuestiones meramente expresivas (Casasús, 1989b).

A esos tres autores pioneros, siguieron otros que podríamos agrupar en dos corrientes:

1. Continuadores, en especial de Martínez Albertos: Aguinaga (2000), Armañanzas y Díaz (1996), Armentia y Caminos (1997), Diezhandino (1994), entre otros, asumieron los planteamientos precedentes sin convertirlos en objeto de reflexión/debate científico. 
Distinto es el caso de Casals $(2004,2005)$, quien abordó de modo específico las cuestiones disciplinares. Definió la redacción periodística - nombre que usa en 2004, y que, en 2005, alterna con el de periodística ${ }^{10}$ - como "una asignatura cuyo corpus teórico quiere sintetizar y desarrollar el conocimiento de la profesión periodística en sus facetas fundamentales: el propio concepto de qué es periodismo, inseparable de una ética y una deontología profesional, y el lenguaje en interacción en la vida social. Esto no significa que sea una especie de derivación de la Lingüística" (Casals, 2004, p. 470).

En lo que respecta a las cuestiones metadisciplinares, consideraba que la disciplina disponía entonces de "un cuerpo docente activo y dinámico" (Casals, 2004, p. 471), que estudia el periodismo, "una actividad que narra, interpreta y juzga el mundo. Describe, explica, muestra y orienta" (Casals, 2005, p. 24), especialmente, el mensaje, en torno al que gravitan otros ámbitos a los que no renuncia: ética, deontología, periodismo, uso de las fuentes, etc., combinando teoría y práctica, y con un enfoque normativo (Casals, 2004, p. 480). También propone el concepto de consiliencia, que es más que interdisciplinariedad: se trata de una visión integral de las disciplinas, formulada por científico Edward O. Wilson, que permite conciliar la independencia del propio campo manteniendo una estrecha interconexión con otras ciencias: pragmática, lingüística, sociología, filosofía y derecho (Casals, 2005, p. 244).

2. Críticos: Borrat (2002), Burguet (1997) y Vidal (2002) participaron en un monográfico sobre cuestiones disciplinares de la revista Anàlisi: Quaderns de comunicació $i$ cultura. ${ }^{11}$ Ninguno puso en duda la existencia de una disciplina universitaria que estudiara el periodismo, pero sí algunos de los conceptos básicos. Vidal (2002), particularmente, se refirió en aquel entonces a lo que definió como un paradigma hegemónico de la redacción periodística, articulado en torno a determinada concepción del lenguaje, del periodismo, de la objetividad y de

10 En 2004, empleará el término de redacción periodística para referirse a la disciplina, mientras que en 2005 usará indistintamente los de periodística y redacción periodística. Por ejemplo: "Para el desarrollo científico de esta disciplina llamada periodística" (Casals, 2005, p. 46).

11 Una reflexión metadisciplinar, crítica y de envergadura, que no ha vuelto a repetirse hasta el momento. 
los géneros periodísticos, ya superados por el empuje de la lingüística y la filosofía contemporánea.

Los planteamientos de Vidal se nutren de Chillón, el primero, más radical y tenaz crítico: ya en 1985 formuló sus primeros reproches a la tradición dominante, que completó en 1999 y reiteró - con cambios menores- en 2011 y 2014. A juicio del profesor catalán, la tradición de los estudios de redacción periodística y de la periodística en España había desarrollado una noción empobrecedora del periodista y del periodismo, imponía un enfoque normativo, concebía la enseñanza como mera formación profesional, recelaba de la teoría - a la que había integrado con los saberes prácticos $-{ }^{12}$ y se había movido entre un empirismo impresionista y un cientifismo retórico, que no había definido adecuadamente ni el objeto de la disciplina ni su constitución teórica y metodológica.

Precisamente, para superar esas debilidades, Chillón planteó abandonar la redacción periodística y la periodística, una "versión maquillada y travestida" de la anterior (2014, p. 109), y crear la comunicación periodística. ${ }^{13}$ Una disciplina que entendiera el periodismo como una mediación cultural, $y$ "no como raso saber hacer instrumental, reducible a un repertorio de fórmulas y recetas 'de oficio"' (p. 432); que lo estudiara con un enfoque descriptivo y analítico (abierto a cualquier medio, no solo el periódico), con el objetivo de "a) describir y analizar lo que efectivamente es, b) proponer lo que podría ser y c) postular lo que debería ser [las cursivas son mías]" (Chillón, 1999, p. 432), e incorporando críticamente saberes de las humanidades y de las ciencias sociales que aplica a sus propios intereses, entre ellos, al nuevo entorno digital; y que se construyera sobre el llamado giro lingǘstico, fruto de la toma de conciencia de que "el lenguaje no es mera-

12 A esa debilidad apuntaba también tres años más tarde Borrat (2002), quien advertía que la disciplina era todavía emergente por dos razones: porque no había logrado integrar el enfoque de quienes la abordaban desde los saberes profesionales y el de quienes combinaban esos saberes con teorías científicas, y porque no se distinguía entre saberes y teorías, ni se estimulaba "la crítica de los saberes desde las teorías y, a la inversa, la crítica de las teorías desde los saberes" (p. 59).

13 Como explica, esa denominación nace a comienzos de la década de 1990 en la Unidad de Redacción Periodística de la Universidad Autónoma de Barcelona para denominar a los docentes del área. Y añade: "Tal cambio no obedeció, como pudiera pensarse, a un mero prurito terminológico, sino a la convicción de que era y es preciso redefinir el campo entero y diverso de los estudios periodísticos — como parte integrante de los estudios de comunicación-, e invocar para su estudio enfoques teóricos y metodológicos multidisciplinarios" (Chillón, 1999, p. 432). 
mente el vehículo o la herramienta con que damos cuenta de las ideas previamente formadas en nuestro magín: estas se forman solo en la medida en que son verbalizadas" (Chillón, 2001, p. 28).

Aparte de que no es el objetivo de este trabajo entrar a fondo en los planteamientos de cada autor, no disponemos del espacio para desarrollar la noción y las implicaciones del giro lingüístico. ${ }^{14}$ La legítima - y también discutible - crítica a los resultados no justifica arrumbar con la tradición de la disciplina; en todo caso, reclamaría una renovación o una redefinición o un cambio de paradigma (como plantea Vidal). En este sentido, la propuesta de Chillón no rompe, a nuestro juicio, con la estructura disciplinar que se había ido construyendo hasta entonces ni justifica un cambio de nombre. Que determinada noción de periodismo pueda ser estrecha o reductiva, que las clasificaciones de los géneros sean normativas o descriptivas, que el uso de las metodologías sea adecuado o no, etc., forma parte del desarrollo de la propia disciplina. En ese sentido, la crítica de Chillón no anula los lineamientos básicos de la periodística tal y como se había ido definiendo:

1. Objeto de estudio: el periodismo en cualquiera de sus plataformas de distribución. La reclamación de Chillón para que el periodismo se estudie en todos los soportes ya la contemplaba Martínez Albertos, quien, por razones de oportunidad (era el más desarrollado entonces), inició su investigación con la prensa.

2. Naturaleza interdisciplinar: una interdisciplinariedad que no niega ninguno de los autores mencionados, como hemos visto. Núñez lo afirmaba de modo tajante: "El enfoque interdisciplinario y el encuentro de las disciplinas es, pues, indispensable tanto para describir el objeto y sus productos como para mostrar las reglas productivas del texto y de su inserción social” (2002, p. 96). En concreto, la teoría del texto y la pragmática (lingüística), la sociología, la teoría de la narración y la teoría de la acción aportan conocimientos y métodos válidos que ayudan a comprender — explicativa y analíticamenteel periodismo como actividad profesional.

14 Y menos las del giro semiolingüístico, que formulará más adelante (Duch y Chillón, 2012, p. 71). 
En los últimos años, López Pan es el autor que más atención ha prestado a las cuestiones metadisciplinares: ha revisado críticamente los trabajos de Martínez Albertos (López Pan, 2009a), Casasús (López Pan, 2010) y Núñez (López Pan, 2015), ha respaldado la propuesta de Casasús (2009) acerca de la denominación más adecuada de la disciplina, ha formulado algunas ideas sobre su estatuto epistemológico y, de la mano de De Lorenzo y López Pan (2017), ha realizado el primer análisis casi exhaustivo de la investigación sobre periodismo en las revistas de comunicación en España. La contribución de este autor, que De Lorenzo (2016, p. 68) califica de "perspectiva histórico-crítica”, sirve de soporte para la segunda parte de este trabajo, que articulamos en torno al objeto y los ámbitos de la disciplina, por un lado, y su naturaleza, por otro. La propuesta, que tiene un punto de balance y señala unos horizontes abiertos, se articula a partir de las reflexiones de los autores mencionados en la apretada síntesis de este primer epígrafe. La filiación de las ideas, aunque nítida, no irá desplegada con detalle para no recargar el texto de referencias bibliográficas y matizaciones.

Una observación de carácter terminológico: coincidimos con López Pan en que el nombre de periodística ${ }^{15}$ propuesto por Casasús es el más indicado: "Acoge todo el ámbito de la tradicional redacción periodística, pero lo desborda programática e intencionalmente: convierte en campo de estudio el periodismo en su conjunto y en sus múltiples facetas" (López Pan, 2009 b, p. 210). De ahí que en la parte propositiva del artículo - y desde el propio título de este epígrafe- usemos el término periodística.

\section{Periodística: objeto, ámbitos y naturaleza}

\section{Objeto y ámbitos}

Todos los autores coinciden en subrayar el carácter autónomo de la periodística (o sus equivalentes). Como tal entidad autónoma,

15 También empleado por otros autores como Jones (1999) y Cantavella y Serrano (2004). El propio Martínez Albertos acepta ese nombre, aunque a su juicio no supone ninguna variación con respecto al de redacción periodística: entiende ambos como simples sinónimos. Por otro lado, a comienzos de la década de 1990, se creó la Sociedad Española de Periodística, que publica las actas de sus congresos bajo el título de Estudios de Periodística y la colección de libros periodística, que también es el nombre de la revista de la Societat Catalana de Comunicació (López Pan, 2009b). 
la Periodística estudia el Periodismo (1) como actividad práctica que se sirve de una variedad de soportes, tradicionales unos (prensa, radio y televisión), más recientes otros (Internet); y lo estudia (2) desde sí mismo, como tal actividad, no como elemento del sistema social (que lo es) ni como elemento de relevancia lingüística (que también lo es), etc. Dicho de otro modo, aborda desde una perspectiva teórica y especulativa - pero también práctica - las cuestiones implicadas en el ejercicio de la profesión periodística: cómo se realiza esa actividad, cómo se ha realizado, cómo debería realizarse, cuáles son sus efectos personales y sociales, etc. (López Pan, 2005, p. 130)

El objeto de la disciplina, así definido por López Pan, quedaría incompleto si no se desciende a líneas de investigación y ámbitos — subdisciplinas, en algunos casos - más representativos (sin pretensión de exhaustividad). ${ }^{16}$ Los que mencionamos siguen los sugeridos por Casasús (1989a y 1991c) y López Pan (2009b), aunque con matices, reformulaciones y ampliaciones. Como se advertirá, no se diferencia entre medios ni plataformas de distribución de contenidos periodísticos. El desarrollo de cada ámbito/línea es muy sintético y meramente descriptivo:

1. Teoría del periodismo: incluiría las reflexiones sobre la propia actividad y la evolución conceptual del periodismo - estudio de los tipos y los modelos de periodismo-y los perfiles profesionales del periodista. En este aspecto, estamos asistiendo a una abundante reflexión e investigación sobre las teorías del periodismo en el entorno digital (Steensen \& Ahva, 2015). También el estudio de la naturaleza de los acontecimientos y de las fuentes, y de los procesos de construcción de la noticia y de la actualidad (newsmaking y newsgathering):

a. La periodística debe desvelar la lógica interna que late en determinados modos de afrontar la actividad periodística. Si esa lógica se muestra, el periodista — también el empresario y el directivoadvertirán qué implican sus decisiones. Para que un profesional actúe en libertad, debe ser plenamente consciente de lo que sustenta su actividad.

16 Por ejemplo, no se menciona la periodística como disciplina, línea en la que se inscribe el presente trabajo. Tampoco el diseño ni la enseñanza del periodismo, líneas de investigación en desarrollo. 
2. Historia del periodismo: a efectos conceptuales, se trataría de que una disciplina, ya desarrollada y plenamente constituida, quedara acogida en la periodística que aquí se propone. Sus contenidos: la evolución del periodismo como profesión desde sus orígenes a la actualidad. Sus protagonistas, tanto personas como instituciones. Incluiríamos aquí el estudio diacrónico de las relaciones entre el periodismo y la literatura: préstamos e influencias mutuas.

3. Redacción periodística: retomaríamos el nombre que se dio a la disciplina los primeros años ( $y$ que algunos siguen usando), porque nuestra tesis es que esa denominación se ajustaba mejor a un aspecto específico, el de la teoría y la práctica de los textos periodísticos. El texto se entiende aquí en un sentido amplio, como noción semiótica, y, por supuesto, abarca todos los soportes: prensa, radio, televisión, internet. Entre otras, esta línea acoge:

a. La crítica de textos y las investigaciones sobre los estilos (también su evolución) y los lenguajes de los distintos medios: escrito, radiofónico, televisivo, web, móvil.

b. Los estudios sobre los géneros periodísticos y su evolución, a los que internet y el periodismo online han dado un nuevo impulso. Sirva de ejemplo el trabajo de Bazaco, Redondo y Sánchez-García (2019) sobre el clickbait como estrategia del periodismo viral.

c. Un lugar específico lo ocuparían los géneros del periodismo literario.

4. Periodismo especializado o información periodística especializada, que también ha adquirido la entidad de disciplina en sí misma. Muñoz Torres, que la bautiza como información periodística especializada, la define como aquella "disciplina que estudia la producción y difusión de textos informativos orientados a divulgar las distintas especialidades del saber experimental, social y humanístico, en función de su pertinencia científica y de su interés, al mayor número posible de personas, de manera principalmente narrativa, a través de los medios de comunicación" (2001, pp. 174 y 175). A nuestro juicio, toda 
la investigación relacionada con las cuestiones que genera la creciente especialización se acogería cómodamente en la disciplina ${ }^{17}$ (se podría hablar de una periodística de los contenidos especializados), sin perder por ello su evidente autonomía que se refleja en su presencia en los planes de estudio, en la creación del Instituto de Estudios de Comunicación Especializada (IECE), del que forman parte profesores de periodismo especializado de distintas universidades públicas y privadas, y en la organización de congresos periódicos.

5. Deontología periodística, que, como en los dos casos anteriores, se trata de una disciplina de pleno derecho que abarca las múltiples cuestiones éticas relacionadas con las decisiones del periodista: objetividad, neutralidad, independencia, conflictos de intereses, privacidad, secreto profesional, ocultación de identidad, plagio, ética del fotoperiodismo, transparencia informativa, etc. Obviamente, las cuestiones suscitadas al respecto conectan con la teoría del periodismo, entre otras razones, porque cualquier juicio sobre sus funciones y sus procederes se asienta sobre una determinada noción de periodismo, implícita o explícita. Esta disciplina resulta especialmente relevante ante los desafíos que impone la profusión de contenidos digitales, muchos de ellos difíciles de contrastar para los periodistas y las audiencias, razón por la que los estudiosos proponen pautas de actuación (Cruz y Suárez, 2017).

Aunque el listado de los ámbitos mencionados podría levantar la sospecha de que nos mueve un afán ilegítimo por allegar a la periodística disciplinas con trayectoria universitaria y un cuerpo disciplinar propio, la realidad es más simple: no se trata de restar autonomía ni de encorsetar esas áreas de investigación (algo, por otro lado, imposible), sino de ampararlas en un marco disciplinar más amplio que aúne investigaciones orientadas al mismo objetivo y con entrecruzamientos evidentes.

17 En la propia justificación del periodismo especializado, se advierte su entroncamiento con la periodística. "Es necesario dotar a los futuros profesionales de la información de herramientas que les capaciten para responder" mejor a la exigencia de la "especialización, tratar con fuentes externas y elaborar textos claros, amplios y divulgativos de los conocimientos específicos” (Elías y Luengo, 2014, p. 27). 


\section{Naturaleza interdisciplinar}

Todos los autores consideran como un rasgo identitario de la periodística la interdisciplinariedad, una interdisciplinariedad "constitutiva — ni provisional ni una serie de disciplinas amalgamadas - [...] imprescindible, por tanto, si esta pretende desplegar toda su tarea reflexiva e ir más allá de la mera descripción de destrezas profesionales” (López Pan, 2014, p. 130).

Lo que sigue desarrolla una propuesta de López Pan, quien agrupa las disciplinas auxiliares en función del tipo de contribuciones al estudio del periodismo. Aquí nos limitamos a esbozar un mapa con las de objeto más amplio, y sin atender a las que se amparan bajo cada una de ellas.

\section{Disciplinas básicas}

Son disciplinas imprescindibles para el estudio de los fundamentos, entre ellas, la lingüística, la filosofía (epistemología, teoría del conocimiento, antropología, ética, etc.), la retórica y la sociología, a las que se acerca el investigador del periodismo de un modo indirecto (que no superficial), porque le permiten conocer mejor la actividad periodística, paso imprescindible para enseñar y para resolver con sólidos fundamentos algunos de los problemas que plantea el ejercicio de la profesión.

Para las relaciones entre la sociología y el periodismo, remitimos a la somera revisión cronológica que ofrecieron en su momento Casasús (1988) y Núñez (2002). En nuestros días, la revolución tecnológica ha traído consigo una abundante investigación sobre qué es el periodismo y qué es ser periodista. Particularmente interesante es la perspectiva sociológica de Carlson \& Lewis (2015), Deuze \& Witschge (2018), Waisbord (2018), entre otros, que plantean que el periodismo se encuentra en un trabajo de fronteras, de delimitación en un nuevo contexto. Sus planteamientos no son éticos o epistemológicos, sino meramente descriptivos.

Desde la perspectiva lingüística, López Pan (2015) destaca precisamente a Núñez, del que señala dos trabajos especialmente relevantes: $L a$ construcción del texto (1991b) y el Manual para periodismo (1991c). También menciona los estudios de Martínez Vallvey (1995) y Vidal (1998) so- 
bre la entrevista, y el de Burguet ${ }^{18}$ (1997) sobre una teoría de la redacción periodística que elabora, por un lado, a partir de la teoría del texto y la filosofía del lenguaje de Austin (que desarrolla y cuya utilidad para el análisis de la información diaria demuestra), y por otro, en diálogo con Núñez y su noción de los contextos.

Es interesante el trabajo que se ha realizado desde la perspectiva de lingüística de la evaluación (Breeze \& Olza, 2017).

Por su parte, en el ámbito anglosajón, se han desarrollado las investigaciones de lingüística aplicada. En este sentido, resulta muy interesante el trabajo de Haapenin (2017) sobre las citas directas en los textos periodísticos: su proceso de decontextualización (extraer la cita del contexto en la que se produce — rueda de prensa o entrevista-), recontextualización (situación dentro del texto periodístico) y textualización (revisión de las palabras para ajustarlas al contexto). En ese proceso, se produce lo que llama la "monologuización", la desaparición del periodista, que genera la impresión de que el entrevistado responde sin que exista una solicitud previa $y$ de un modo continuado.

Entre los ejemplos de investigaciones tributarias de la filosofía, mencionaremos a Del Rey (1988), quien prescinde intencionadamente de los especialistas de la materia para ofrecer un punto de vista epistemológico externo a la disciplina. Del Rey situará en el centro de la redacción periodística los géneros, instrumentos del periodista para atrapar la realidad y las categorías que sirven para justificar su carácter científico. En este sentido, Del Rey se muestra cercano a la escuela de la Universidad Complutense.

Una perspectiva también vinculada a la filosofía (teoría del conocimiento) es la de Vidal (2002), del que ya hemos mencionado su trabajo sobre el estatuto de la redacción periodística y sobre los presupuestos epistemológicos en los que se funda el periodismo. Un último ejemplo entre muchos, de aproximación desde la filosofía, es el de Chillón (2010), quien

18 Si no lo hemos mencionado antes es porque el planteamiento de Burguet se centra en la redacción periodística como asignatura y no tanto en la disciplina. Su objetivo es "hacer explícito el proceso implícito en la fabricación de la actualidad, que también es una manera de construir el mundo. Mejor dicho un [las cursivas son mías] mundo” (1997, p. 8). De ahí que sus explicaciones se limiten a la construcción del texto. 
aborda con las herramientas y los conocimientos filosóficos algunos conceptos básicos, la dimensión moral y la praxis concreta del periodismo.

Por último, en la periodística, junto con el estudio de las estructuras retóricas de los medios y de los textos noticiosos, se ha desarrollado en los últimos años un interés creciente por los textos periodísticos de opinión, en particular la columna.

\section{Disciplinas paralelas}

Junto con las disciplinas mencionadas, la reflexión sobre el periodismo puede recibir una ayuda notable de los estudios sobre la literatura y sobre la historia. Tanto los estudios literarios como la historiografía abordan cuestiones muy cercanas a las que caen - o deben caer - bajo el foco de la periodística: la noción de acontecimiento y de acción humana, el carácter narrativo o expositivo y argumentativo de los textos, la objetividad y la verdad, el estatuto de los géneros, etc. Y quienes estudian esas cuestiones desde las disciplinas básicas mencionadas arriba acumulan una tradición más rica que la nuestra.

Una observación antes de adentrarnos en algunas de las aportaciones. Obviamente, las reflexiones desde la literatura y la historiografía se apoyan sustancialmente en la filosofía, la lingüística, la retórica y la sociología. Así, respecto de la literatura, la importancia de la filosofía — al margen de que cualquier teoría sobre el sentido de una actividad ya es filosofía en ejercicio- se demuestra desde los primeros tiempos con la atención que le prestaron Platón y, especialmente, Aristóteles. Por otro lado, en el ámbito de los estudios sobre crítica literaria y teoría de la literatura, adquiere un especial relieve la aportación de los lingüistas, en especial la lingüística estructuralista: tan es así que algunos afirman que la aplicación de la lingüística a la literatura es la que permite el paso de una crítica impresionista de las obras a otra más seria - ¿científica? - y justificada. También en el ámbito de la historia operan simultáneamente dos disciplinas básicas: la filosofía y la lingüística, y una tercera paralela: la literatura. Más aún, en algunos casos son filósofos, lingüistas o estudiosos de la literatura quienes se acercan a la historia para entenderla con las herramientas intelectuales de sus disciplinas de origen. 
Desde lo que aquí entendemos como periodística, ha sido Chillón ${ }^{19}$ (1999) quien ha realizado las aportaciones más abundantes y sólidas sobre las relaciones entre periodismo y literatura. ${ }^{20}$ No hay duda de que la tarea que emprendió en 1985 le otorga el privilegio de ser el autor con más trabajos descriptivos, teóricos y metodológicos al respecto. También a Chillón (1989, pp. 115-122) se debe una original línea de investigación: la que denomina el comparativismo periodístico-literario, a la que asignaba un doble objetivo: estudiar el legado que la cultura periodística ha recibido de la tradición literaria y el que los estudios de periodismo - "comparativamente adolescentes y faltos de rigor" - podrían recibir de los estudios literarios (pp. 122-127). En definitiva, descubrir cómo ha influido la literatura en el periodismo y aplicar al periodismo los instrumentos conceptuales y de análisis desarrollados por la teoría literaria.

Analizar y describir las relaciones entre ambas actividades y reflexionar sobre ellas suscita "preguntas capitales sobre la naturaleza de ambas actividades, dudas e interrogantes que" hacen tambalearse los cimientos de los estudios literarios y periodísticos. Por otro lado, obliga a preguntarse "qué significa, qué implicaciones estéticas y cognitivas tiene el acto de empalabrar 'la realidad' con y en [las cursivas son mías] enunciados lingüísticos" (Chillón, 1999, p. 394).

En cuanto a la historiografía, a título de ejemplo, mencionamos algunas cuestiones que podrían enriquecerse con autores como Carr (1986) o White (1999, 2003), por citar algunos:

1. La noción de acontecimiento: de las respuestas que se han dado desde la historiografía — muy atenta a la teoría de la acción — a las preguntas sobre qué es un acontecimiento histórico o cómo marcar sus límites temporales pueden sacar mucho provecho los estudiosos del periodismo: también, ellos, por supuesto, acudiendo en directo a la mencionada teoría de la acción, deben interrogarse por el acontecimiento periodístico, por sus límites, por la sucesión de la actualidad, etc.

19 Dicho sea de paso, en sus trabajos resulta transparente la relevancia de la lingüística y de la filosofía.

20 A su juicio, las relaciones entre ambas actividades culturales no habían recibido una atención adecuada. Y no le faltaba razón como lo demuestra que ninguno de los autores estudiados en los distintos artículos de este proyecto lo aludía a esa relación más allá del mero trazado de fronteras entre ambas. 
2. Las fuentes — valor, credibilidad, la memoria, etc. - a las que se ha prestado atención desde la historia.

3. Las nociones de explicación, interpretación y comprensión que los historiadores — al amparo de la filosofía — se han planteado en su ámbito que da cuenta de las acciones humanas.

4. Sobre la noción de la trama: en este sentido, la historiografía con sus reflexiones sobre cómo construir la historia nos lleva la delantera en cuestiones como las que siguen: ¿qué es la trama?, ¿es algo que se impone a los acontecimientos y las acciones o la descubrimos en ellos?, ¿es algo reclamado por los acontecimientos, pero construido por nosotros $^{21}$ ? (Ricoeur, 1990). La respuesta a estas preguntas es muy relevante: el periodista (lo sepa o no, lo quiera o no), de hecho, está continuamente construyendo tramas y dándoles encarnadura textual.

Tanto Núñez (2002, 2004a) como Chillón (2014) han recurrido a una interdisciplinariedad profunda, sistemática y articulada. Más allá de sus aportaciones ya mencionadas en el ámbito de las relaciones entre el periodismo y la literatura, habría que destacar la obra que publica con Lluís Duch (2012), Un ser de mediaciones: antropología de la comunicación. En ese excelente trabajo, cuyo objeto es más amplio que el de la periodística, se abordan asuntos nucleares del periodismo, entre otros, la naturaleza de los hechos sociales, la construcción de la trama (en continuidad con los planteamientos de Ricoeur), la representación, la falsa dicotomía ficción-no ficción/ficción-realidad, la temporalidad o la razón narrativa.

Como se advierte de este repaso, la interdisciplinariedad — constitutiva de la periodística - reclama una metodología muy diversa, abierta a cualquiera de los métodos cuantitativos y cualitativos de las ciencias sociales y de las humanidades. Encuestas, cuestionarios, entrevistas (estructuradas, semiestructuradas y libres), estudios de caso, etnografía, observación (participativa o no), análisis de contenido, análisis del discurso, etc., están al servicio de los objetivos y de la naturaleza de cada investigación.

21 Si se defiende que la trama se descubre en los acontecimientos o es algo reclamado por ellos, no cabría entenderla como una imposición caprichosa, ideológica o interesada, y, por tanto, relativa. Eso tampoco tiene por qué implicar que los acontecimientos respondan a una única trama: podrían ofrecer más tramas en función de las preguntas que les planteemos. 


\section{Conclusiones}

La preocupación por dotar al periodismo de un estatuto disciplinar ha estado siempre presente en Hispanoamérica y España, pero, sobre todo, con el paso de las escuelas a las universidades. En ese paso, en ese gozne, España se caracteriza por haber generado un debate y una discusión apenas existente en Hispanoamérica.

Las primeras reflexiones metadisciplinares acerca del periodismo como área de conocimiento en la universidad española se dan el ámbito de la redacción periodística, heredera de la asignatura que con ese mismo nombre formaba parte de los planes de estudio de las escuelas de periodismo, germen de las facultades creadas en 1971.

Los pioneros - Gomis (1974, 1989, 1991, 2002), Martínez Albertos (1974, 1989a y 1989b, 1992), Núñez (1977, 1979, 1991a, 1991b, 1991c, 1995, 2002, 2004a, 2004b, 2007) y Casasús $(1987,1988,1989$ a, 1989b, 1991a, 1991b, 1991c) - compartían la convicción intelectual de que cabía una disciplina universitaria autónoma, con entidad docente y un horizonte de investigación propio. También coincidían en caracterizarla como necesariamente interdisciplinar.

Entre los distintos nombres con que se ha bautizado la disciplina, el de redacción periodística, sobre todo, los primeros años, y el de periodística, más recientemente, son los más aceptados. En la propuesta, se opta por el segundo, que no orilla o margina todos esos aspectos no estrechamente ligados a lo lingüístico.

A inicios de la primera década del siglo XXI, cuaja una corriente crítica —Chillón $(1989,1999,2014,2017)$, Vidal $(1998,2002)$ y Burguet (1997) —, con la tradición anterior, cuyos presupuestos epistemológicos y categorías rechaza. Chillón intenta despegarse de esa tradición proponiendo como alternativa la comunicación periodística. Por nuestra parte, sostenemos que nada justifica la creación de una nueva disciplina: de hecho, sus observaciones forman parte de la disciplina cuyos resultados considera insuficientes. En este sentido, nos parece más adecuada la idea del cambio de paradigma que plantea Vidal. 
La periodística que aquí se propone se articula a partir de las reflexiones de los autores que se han detenido en los asuntos metadisciplinares. En este sentido, contribuye a integrar esa tradición:

1. Objeto de estudio: el periodismo como fenómeno de mediación cultural difundido a través de cualquier plataforma (Chillón, 2014, p. 432).

2. Ámbitos: teoría del periodismo, historia del periodismo, escritura periodística/redacción periodística, deontología periodística, periodismo especializado, entre otros. Se propone ampararlos en un marco disciplinar más amplio que aúne investigaciones orientadas al mismo objetivo y con entrecruzamientos evidentes.

3. Naturaleza interdisciplinar: se sirve de las herramientas conceptuales y un utillaje intelectual que le aportan otras disciplinas: básicas unas (filosofía, sociología, lingüística, entre otras) y paralelas otras (historiografía y teoría de la literatura). Esa interdisciplinariedad se aleja de la que critica García-Noblejas (2000), es decir, no consiste en una "combinatoria de algunas disciplinas implicadas en los fenómenos comunicativos" (p. 38), ni en una simple promiscuidad propia de una fase provisional. Tampoco entendemos la periodística como esa especie de arlequín interdisciplinar del que habla el mismo autor, y que describe peyorativamente así:

Un retazo de historia por aquí, otro de lingüística por allá, un remiendo de política a la altura del pecho, un recosido de derecho por la espalda, un retal de ética en el cuello, unos ribetes técnicos en las mangas y perneras [...], y el resto, la inspiración artística (la piel desnuda) del que —no se sabe cómo ni por qué- con la genialidad romántica del comunicador incluida. (p. 39)

4. Metodología variada: métodos filosóficos e historiográficos, crítica textual, el análisis de contenido, el análisis del discurso, la observación participativa, la entrevista en cualquiera de sus modalidades (estructurada, semiestructurada y libre), y cualquier otro de las ciencias sociales y las humanidades. 


\section{Referencias}

Aceves, E. (1963). Introducción al periodismo. Ciudad de México, México: Universidad Nacional Autónoma de México.

Aguinaga, E. de (2000). Nuevo concepto de redacción periodística. Estudios sobre el Mensaje Periodístico, 6, 307-325. https:// revistas.ucm. es/index.php/ESMP/article/view/ESMP0000110307A

Arfuch, L. (1995). La entrevista, una invención dialógica. Barcelona, España: Paidós.

Armañanzas, E. y Díaz, J. (1996). Periodismo y argumentación: géneros de opinión. Bilbao, España: Universidad del País Vasco.

Armentia, J. I. y Caminos, J. M. (1997). La información: redacción y estructuras. Bilbao, España: Universidad del País Vasco.

Ávila, F. (1963). El periodismo y su filosofía. Buenos Aires, Argentina: Tacarigua.

Bazaco, A., Redondo, M. y Sánchez-García, P. (2018). El clickbait como estrategia del periodismo viral: concepto y metodología. Revista Latina de Comunicación Social, 74, 94-115. https://doi.org/10.4185/ RLCS-2019-1323

Bell, A. (1991). The language of news media. Oxford, RU: Backwell.

Bernal, S. y Chillón, L. A. (1985). Periodismo informativo de creación. Barcelona, España: Mitre.

Bond, F. y Rivers, W. (1969). Periodismo. Ciudad de México, México: PaxMéxico.

Borrat, H. (2002). Paradigmas alternativos y redefiniciones conceptuales en comunicación periodística. Anàlisi: quaderns de comunicació $i$ cultura, 28, 55-77. https://www.raco.cat/index.php/Analisi/article/view/15102 
Borrego, S. (1963). Periodismo trascendente. Ciudad de México, México: Jus.

Breeze, R. \& Olza, I. (Eds.) (2017). Evaluation in media discourse: European perspectives. Berna, Suiza: Peter Lang.

Burguet, F. (1997). Construir les notícies: una teoria de la redacció periodística. Barcelona, España: Dèria.

Calsamiglia, H., Cots, J., Lorda, C. U., Nussbaum, L., Payrató, L. \& Tusón, A. (1997). La parla com a espectacl e Estudi d'un debat televisiu. Bellaterra, España: Universitat Autònoma de Barcelona.

Carlson, M.y Lewis, S. C. (Eds.) (2015). Boundaries of journalism: Professionalism, practices and participation. Abingdon, EE. UU.: Routledge.

Carr, D. (1986). Time, narrative, and history. Bloomington, EE. UU.: Indiana University Press.

Casals, M.J. (2004). La enseñanza del periodismo: universidad, conceptos, modelos y redacción periodística. En M.J. Casals (Coord.), Mensajes periodísticos y sociedad del conocimiento: libro homenaje al profesor José Luis Martínez Albertos (pp. 465-485). Madrid, España: Fragua.

Casals, M. J. (2005). Periodismo y sentido de la realidad: teoría y análisis de la narrativa periodística. Madrid, España: Fragua.

Casasús, J. M. (1987). El pensament periodístic a Catalunya: assaig sobre l'evolució de les idees teóriques i professionals en materia de periodismo. Barcelona, España: Curial Edicions Catalanes.

Casasús, J. M. (1988). Iniciación a la periodística: manual de comunicación escrita y redacción periodística informativa. Barcelona, España: Teide.

Casasús, J. M. (1989a). La periodística de la recepción como alternativa global a los estudios tradicionales sobre redacción periodísti- 
ca. Comunicación y Sociedad, 2, 95-112. https://dadun.unav.edu/ handle/10171/7887

Casasús, J. M. (1989b). La sistematittzació dels estudis sobre Història i crítica de la periodística. Periodística, 1, 97-111. https://www.raco. cat/index.php/Periodistica/article/view/17895

Casasús, J. M. (1991a). Análisis y métodos de la periodística. En Casasús, J. M. y Núñez Ladevéze, L., Estilo y géneros periodísticos (pp. 6184). Barcelona, España: Ariel.

Casasús, J. M. (1991b). Evolución de los estudios de periodística. En Casasús, J. M. \& Núñez Ladevéze, L., Estilo y géneros periodísticos. En J. M. Casasús y L. Núñez Ladevéze, Estilo y géneros periodísticos (pp. 37-59). Barcelona, España: Ariel.

Casasús, J. M. (1991c). Evolución y prospectiva del periodismo. En J. M. Casasús y L. Núñez Ladevéze, Estilo y géneros periodísticos (pp. 1035). Barcelona, España: Ariel.

Centro Latinoamericano de Estudios Superiores de Periodismo. (s. f.). Nuestra historia. https://ciespal.org/historia/

Charnley, M. V. (1971). Periodismo informativo. Buenos Aires, Argentina: Troquel.

Chillón, A. (1989). Què pot manllevar el periodisme a la literatura? Propostes per a la fonamentació del comparatisme periodístico-literari. Periodística, 1, 113-128. https://repositori.upf.edu/ handle/10230/40416

Chillón, A. (1999). Literatura y periodismo: una tradición de relaciones promiscuas. Bellaterra, España: Universitat Autònoma de Barcelona.

Chillón, A. (2001). El "giro lingüístico" en periodismo y su incidencia en la comunicación periodística. Cuadernos de Información, 14, 24 47. https://doi.org/10.7764/cdi.14.180 
Chillón, A. (2010). Filosofía del periodismo: razón, libertad, información. Madrid, España: Fragua.

Chillón, A. (2014). La palabra facticia: literatura, periodismo y comunicación. Bellaterra, España: Universitat Autònoma de Barcelona.

Chillón, A. (2017). El concepto de 'facción': índole, alcance e incidencia en los estudios periodísticos y literarios. Cuadernos de Información, 40, 91-105. https://doi.org/10.7764/cdi.40.1121

Copple, N. (1968). Un nuevo concepto de periodismo. Ciudad de México, México: Fax.

Cortez, R. (1961). Introducción al periodismo. Santiago de Chile, Chile: Editorial Universitaria.

Cruz Álvarez, J. y Suárez Villegas, J. C. (2017). Pautas deontológicas para el periodismo digital. El Profesional de la Información, 26(2), 249254. https://doi.org/10.3145/epi.2017.mar.11

Decreto 2070/1971, de 13 de agosto, por el que se regulan los estudios de Periodismo y demás medios de comunicación social en la Universidad.

Deuze, M. \&Witschge, T. (2018). Beyond journalism: Theorizing the transformation of journalism. Journalism, 19(2), 165-181. https://doi. org/10.1177/1464884916688550

Diezhandino Nieto, M. P. (1994). El quehacer informativo. El arte de escribir un texto periodístico: algunas nociones válidas para periodistas. Bilbao, España: Universidad del País Vasco.

Duch, L. y Chillón, A. (2012). Un ser de mediaciones: antropología de la comunicación 1. Barcelona, España: Herder.

Elías, C. y Luengo Cruz, M. (2014). Periodismo especializado y áreas de especialización en currículo de los grados de periodismo en las 
universidades españolas. En F. Esteve Ramírez y J. C. Nieto Hernández (Eds.), Nuevos retos del periodismo especializado (pp. 2334). Madrid, España: Schedas.

Esteve Ramírez, F. y Nieto Hernández, J. C. (Eds.) (2014). Nuevos retos del periodismo especializado. Madrid, España: Schedas.

García-Noblejas, J. J. (2000). Saber y autoridad en el periodismo: no basta la "ausencia de malicia". En Autor, Comunicación borrosa: sentido práctico del periodismo y de la ficción cinematográfica (pp. 25-78). Pamplona, España: Eunsa.

Gomis Sanahuja, L. (1974). El medio media: la función política de la prensa. Madrid, España: Seminarios y Ediciones.

Gomis Sanahuja, L. (1989). Teoria dels gèneres periodístics. Barcelona, España: Centre d'Investigació de la Comunicació.

Gomis Sanahuja, L. (1991). Teoría del periodismo: cómo se forma el presente. Barcelona, España: Paidós.

Gomis, L., Martínez Albertos, J. L., Núñez Ladevéze, L. y Casasús, J. M. (2002). Encuesta: ¿vive la comunicación periodística un cambio de paradigma? Anàlisi: quaderns de comunicació i cultura, 28, 157-185.

Hall, K. y Merino, R. (1995). Periodismo y creatividad. Ciudad de México, México: Trillas.

Haapanen, L. (2017). Monologisation as a quoting practice: Obscuring the journalist's involvement in written journalism. Journalism Practice, 11(7), 820-839. https://doi.org/10.1080/17512786.2016.1208057

Hohenberg, J. (1962). El periodista profesional: guía para el reportero moderno. Ciudad de México, México: Letras. 
Jones, D. E. (1998). Investigación sobre comunicación en España: evolución y perspectivas. Zer: Revista de estudios de comunicación, 3(5), 1351.https://www.ehu.eus/ojs/index.php/Zer/article/view/17359

Johnson, S. y Harris, R. (1970). El reportero profesional. Ciudad de México, México: Trillas.

Lazcano, D. (2013). Análisis de la cobertura periodística de La Vanguardia y $A B C$, sobre la creación de las facultades de ciencias de la información en España (curso académico 1971-1972). RIHC: Revista Internacional de Historia de la Comunicación, 1(1), 176-200. https:// doi.org/10.12795/RiHC.2013.101.09

Leñero, V. y Marín, C. (1986). Manual de periodismo. Ciudad de México, México: Grijalbo.

López, X. (2010). La formación de los periodistas en el siglo XXI en Brasil, España, Portugal y Puerto Rico. Revista Latina de Comunicación Social, 65, 231-243. https://doi.org/10.4185/RLCS-65-2010896-231-243

López, F. (2002). Las citas directas en el periodismo escrito: literalidad y objetividad a la luz de los estudios lingüísticos. Comunicación y Sociedad, 15(2), 79-93. https://dadun.unav.edu/handle/10171/7997

López, F. (2005). Siete décadas de la periodística como disciplina universitaria. En M. I. de Salas Nestares, A. B. Fernández Souto y F. Martínez Vallvey (Coords.), La universidad en la comunicación: la comunicación en la universidad (pp. 129-140). Madrid, España: Edipo.

López, F. (2006). La utilidad del análisis del discurso para la teoría y la práctica del periodismo. En M. Casado Velarde, R. González Ruizy M. V. Romero Gualda (Coords.), Análisis del discurso: lengua, cultura, valores: Actas del I Congreso Internacional (pp. 101-110). Madrid, España: Arco/Libros. 
López, F. (2009a). La centralidad de las formas expresivas y los géneros periodísticos: Martínez Albertos y el estatuto de la redacción periodística. Comunicación y Pluralismo, 8, 9-28. https://dadun.unav. edu/handle/10171/34915

López, F. (2009b). La redacción periodística como disciplina: una historia pendiente. Textual \& Visual Media, 2, 201-214. http://textualvisualmedia.com/index.php/txtvmedia/article/view/35

López, F. (2010). La periodística y sus partes: la propuesta de Josep Maria Casasús. Sphera Publica, 10, 237-258. http://sphera.ucam.edu/index.php/sphera-01/article/view/105

López, F. (2014). Aproximación a la lingüística como disciplina esencial para la periodística. En C. Pérez-Salazar y I. Olza (Eds.), Del discurso de los medios de comunicación a la lingüística del discurso (pp. 129-140). Berlín, Alemania: Frank\&Time.

López, F. (2015). La apuesta por la interdisciplinariedad en los estudios de periodismo en la obra de Luis Núñez-Ladevéze. Doxa Comunicación, 21, 187-198. https://doi.org/10.31921/doxacom.n21a8

Lorenzo, I. de y López Pan, F. (2017). Presencia de la investigación en periodística en libros (1889-2012) y artículos en revistas españolas de comunicación (1980-2012). Estudios sobre el Mensaje Periodístico, 23, 457-476. https://doi.org/10.5209/ESMP.55607

Lorenzo Rodríguez, I. de (2016). Evolución de la periodística en España: estudio descriptivo y temático de libros (1889-2012) y artículos en revistas españolas de Comunicación (1980-2012) (Tesis doctoral, Universidad de Navarra, Pamplona, España).

Martínez Albertos, J. L. (1974). Redacción periodística: los estilos y los géneros en la prensa escrita. Barcelona, España: ATE. 
Martínez, J. L. (1978). La noticia y los comunicadores públicos: lenguaje, estilos y géneros periodísticos en prensa, radio, televisión y cine. Madrid, España: Paraninfo.

Martínez, J. L. (1989a). Editorial. Revista de Ciencias de la Información, 5, 9-14.

Martínez, J. L. (1989b). El lenguaje periodístico. Madrid, España: Paraninfo.

Martínez, J. L. (1992). Curso general de redacción periodística: lenguaje, estilos y géneros periodísticos en prensa, radio, televisión y cine. Madrid, España: Paraninfo.

Martínez, M. (2006). Masa (en situación) crítica: la investigación sobre periodismo en España: comunidad científica e intereses de conocimiento. Anàlisi: Quaderns de comunicación i cultura, 33, 135-170. https://ddd.uab.cat/record/12837

Martínez, F. (1995). La entrevista periodística desde el punto de vista conversacional. Salamanca, España: Universidad Pontificia de Salamanca.

Mellado, C. (2009). Periodismo en Latinoamérica: revisión histórica y propuesta de un modelo de análisis. Comunicar, 17(33), 193-201. https://doi.org/10.3916/c33-2009-01-011

Miller, C. G. (1955). Modern Journalism. Nueva York, EE. UU.: Henry Holt.

Mott, F. L. (1962). The news in America. Cambridge, EE. UU.: Harvard University Press.

Muñoz, J. R. (1992). Notas acerca del estatuto epistemológico de los estudios sobre la información. En AA. VV., Estudios en honor de Luka Brajnovic (pp. 571-599). Pamplona, España: Eunsa.

Muñoz, J. R. (1995). Objetivismo, subjetivismo y realismo como posturas epistemológicas sobre la actividad informativa. Comunicación y Sociedad, 8(2), 141-171.https://dadun.unav.edu/handle/10171/8542 
Muñoz, J. R. (2000). Concepciones epistemológicas implícitas en los libros de estilo de El País, El Mundo y ABC. Zer: Revista de estudios de comunicación, 9, 277-318. https://www.ehu.eus/ojs/index.php/ Zer/article/view/17438/0

Muñoz, J. R. (2001). Clarificaciones conceptuales sobre información periodística especializada. En G. Galdón (Coord.), Introducción a la comunicación y la información, (pp. 159-174). Barcelona, España: Ariel.

Muñoz, J. R. (2002a). Objetividad y verdad: sobre el vigor contemporáneo de la falacia objetivista. Revista de Filosofía, 27(1), 161-190. https://revistas.ucm.es/index.php/RESF/article/view/RESF0202120161A

Muñoz, J. R. (2002b). Por qué interesan las noticias: un estudio de los fundamentos del interés informativo. Barcelona, España: Herder.

Nixon, R. B. (1982). Historia de las escuelas de periodismo. Chasqui. Revista Latinoamericana de Comunicación, 2, 13-19. https://revistachasqui.org/index.php/chasqui/article/view/946

Núñez, L. (1977). Lenguaje y comunicación: para una teoría de la redacción periodística. Madrid, España: Pirámide.

Núñez, L. (1979). El lenguaje de los "media": introducción a una teoría de la actividad periodística. Madrid, España: Pirámide.

Núñez, L. (1991a). Estilo, texto y contexto en periodismo. En J. M. Casasús y L. Núñez Ladevéze, Estilo y géneros periodísticos (pp. 99-181). Barcelona, España: Ariel.

Núñez, L. (1991b). La construcción del texto. Madrid, España: Eudema.

Núñez, L. (1991c). Manual para periodismo: veinte lecciones sobre el contexto, el lenguaje y el texto de la información. Barcelona, España: Ariel. 
Núñez, L. (1995). Introducción al periodismo escrito. Barcelona, España: Ariel.

Núñez, L. (2002). Encuentro entre teoría y práctica del periodismo desde un enfoque interdisciplinario. Anàlisi: Quaderns de comunicació $i$ cultura, 28, 79-96. https://ddd.uab.cat/record/855

Núñez, L. (2004a). El periodismo desde un enfoque interdisciplinar. En J. Cantavella y J. F. Serrano (Coords.), Redacción para periodistas: informar e interpretar (pp. 17-50). Barcelona, España: Ariel.

Núñez, L. (2004b). Pasado, presente y futuro de la libertad de expresión: los hechos no son libres, ni las opiniones sagradas. Telos: Cuadernos de comunicación e innovación, 8, 49-62.

Núñez, L. (2007). Los géneros periodísticos y la opinión. En J. Cantavella y J. F. Serrano (Coords.), Redacción para periodistas: opinar y argumentar (pp. 15-54). Madrid, España: Universitas.

Rae, W. (1952). Editing small newspaper: A basic handbook for journalists. Nueva York, EE. UU.: M.S. Mill Company.

Reschke, L. K. (1951). The newspaper in the class-room. Milwakee, EE. UU.: North American Press.

Rey, J. del (1988). Estatuto epistemológico de la redacción periodística. Revista de Ciencias de la Información, 5, 113-122.

Rivers, W. L. (1969): Periodismo: prensa, radio y TV. México: Pax-México.

Rivers, W. L. y Schramm, W. (1973). Responsabilidad y comunicación de masas. Buenos Aires: Ediciones Troquel

Ricoeur, P. (1990). Historia y verdad. Madrid, España: Encuentro.

Ricoeur, P. (1999). Historia y narratividad. Barcelona, España: Paidós. 
Ricoeur, P. (2000). Mémoire, histoire, oubli. París, Francia: Seuil.

Ricoeur, P. (2003). La memoria, la historia y el olvido (A. Neira, trad.). Madrid, España: Trotta.

Río Reynaga, J. del (1978). Géneros interpretativos (El reportaje). Quito, Ecuador: Época.

Rivadeneira Prada, R. (1977). Periodismo: la teoría general de los sistemas y la ciencia de la comunicación. Ciudad de México, México: Trillas.

Rojas Avendaño, M. (1976). El reportaje moderno. Ciudad de México, México: Universidad Nacional Autónoma de México.

Romero, L. A. (1959). Curso práctico de periodismo. Buenos Aires, Argentina: Hobby.

Romero, L. (Coord.) (2006a). Espejismos de papel: la realidad periodística. Ciudad de México, México: Universidad Nacional Autónoma de México.

Romero, L. (2006b). La realidad construida en el periodismo: reflexiones teóricas. Ciudad de México, México: Universidad Nacional Autónoma de México.

Santamarina, C. (1960). Manual de periodismo. Buenos Aires, Argentina: Pan América.

Santibáñez M., A. (1974). Periodismo interpretativo: los secretos de la fórmula Time. Santiago de Chile, Chile: Andrés Bello.

Steensen, S. \& Ahva, L. (2015). Theories of journalism in a digital age: An exploration and introduction. Journal Digital Journalism, 3(1). https://doi.org/10.1080/21670811.2014.927984 
Steinberg, C. S. y Bluem, A. W. (Eds.) (1972). Los medios de comunicación social. Ciudad de México, México: Roble.

Ulibarri, E. (1994). Idea y vida del reportaje. Ciudad de México, México: Trillas.

Vidal, D. (1998). La entrevista en prensa. En A. Balsebre, M. Mateu y D. Vidal, La entrevista en radio, televisión y prensa (pp. 245-409). Madrid, España: Cátedra.

Vidal, D. (2002). La transformació de la teoria del periodisme: una crisi de paradigma? Anàlisi: Quaderns de comunicació i cultura, 28, 2154.https://www.raco.cat/index.php/analisi/article/view/15101

Waisbord, S. (2018). Truth is what happens to news: On journalism, fake news, and post-truth. Journalism Studies, 19(13), 1866-1878. https://doi.org/10.1080/1461670X.2018.1492881

Weill, G. (1941). El diario: historia y función de la prensa periódica. México: Fondo de Cultura Económica.

Westley, B. 1953. News editing. Nueva Delhi, India: Oxford \& IBH.

White, H. (1999). Figural realism: Studies in the mimesis effect. Baltimore, EE. UU.: Johns Hopkins University Press.

White, H. (2003). El texto histórico como artefacto literario. Barcelona, España: Paidós.

Zelizer, B. (2014). Taking journalism seriously: News and the academy. Thousand Oaks, EE. UU.: Sage. 